\title{
0362 WORK-RELATED ROAD TRAFFIC INJURIES IN TANZANIA: EVIDENCE FOR IMPROVING WORKERS COMPENSATION LAW IN DEVELOPING COUNTRIES
}

Y M Kishashu*, A Franzblau, T Robins, G Smith Correspondence: Department of Environmental and Occupational Health, School of Public Health and Social Sciences, Muhimbili University of Health and Allied Sciences, United Nations Road, P. O. Box 65015, Dar Es Salaam, Tanzania

10.1136/ip.2010.029215.362

Background Work-related road traffic injuries represent a considerable burden to society, affecting people in the most productive years of their lives. Severe work-related injuries and the resulting adverse socio-economic impacts, represent a special burden to developing countries. This study, which was conducted in Tanzania, sought to describe patterns of severe traumatic work-related injuries; identify their causes and risk factors; evaluate the quality of reporting workrelated injuries and; identify strategies for their prevention and control in Tanzania and other developing countries.

Methods Data were collected through structured interviews with 1385 injury cases admitted in the largest trauma hospital in Tanzania from March 2007 to March 2008. Detailed information was collected after work-relatedness of a case was established. Information from interviews was linked with hospital records, workers compensation and police data.

Findings A total of $638(46 \%)$ injury cases were classified as work-related injuries, and majority were male-workers (93\%). Road traffic injury was the most common reason for admission $(62 \%)$ followed by falls $(15 \%)$. Road was the leading place of injury $(64 \%)$ followed by work premises $(27 \%)$. Walking on the road side was the most common activity at the time of injury (33.5\%) followed by travelling (28.4\%).

Conclusions The study revealed need for improving workers compensation law in Tanzania and other developing countries in order to cover more workers. From this new evidence, commuting injuries are now covered under the new workers compensation legislation in Tanzania. 